\title{
Analytical Stability Indicative Method Development and Validation by High Pressure Liquid Chromatography for Assay in Ciprofloxacin hydrochloride Drug Substances
}

\author{
S. Shrinivas, M. Revanasiddappa* \\ Department of Engineering Chemistry, PESIT Bangalore South Campus, Bangalore, India \\ Email: " revanasiddappam@pes.edu
}

Received 25 June 2015; accepted 9 August 2015; published 12 August 2015

Copyright (C) 2015 by authors and Scientific Research Publishing Inc.

This work is licensed under the Creative Commons Attribution International License (CC BY). http://creativecommons.org/licenses/by/4.0/

(c) (i)

Open Access

\begin{abstract}
Ciprofloxacin is an antibiotic generic drug that can treat a number of bacterial infections. It is a second generic fluoroquinolone. This work presents a simple, sensitive and stability indicative method for assay determination of drug substances ciprofloxacin hydrochloride by high pressure liquid chromatography (HPLC). Separation of impurities from the main drug substances and accurate assay quantification with a simple method is difficult by Spectrophotometry. The separation of co-eluents and impurities from the ciprofloxacin drug substances was archived by HPLC with simple mobile phase $0.15 \%$ orthophosphoric acid adjusted $\mathrm{pH}$ to 3.0 with triethylamine and acetonitrile using a gradient program, column inertsil C18, $250 \mathrm{~mm} \times 4.0 \mathrm{~mm}, 5 \mu \mathrm{m}$. Flow rate was $0.7 \mathrm{~mL} / \mathrm{min}$, the column temperature and injection volume were $35^{\circ} \mathrm{C}$ and $10.0 \mu \mathrm{L}$. Chromatographic analysis was carried out at wavelength $278 \mathrm{~nm}$. The developed method was validated according to the international conference on harmonization (ICH) guidelines regarding: Precision, specificity by degradation, linearity, accuracy, range and robustness. The proposed method showed good linearity (correlation coefficient and regression coefficient were not less than 0.999 and 0.998 ) in the range of $50 \%$ to $150 \%$ of working concentration. The recovery at $50 \%, 100 \%$ and $150 \%$ of working concentration level was within $98.0 \%$ to $102.0 \%$. The range of the method is concluded that developed method is from $50 \%$ to $150 \%$ of target concentration for ciprofloxacin hydrochloride. The applicability of the proposed method was verified through the analysis of the samples and percentage recoveries in the range of $98 \%$ to $102 \%$ were obtained without any interference detected at the main peak in the chromatogram. The validated method is highly selec-
\end{abstract}

"Corresponding author.

How to cite this paper: Shrinivas, S. and Revanasiddappa, M. (2015) Analytical Stability Indicative Method Development and Validation by High Pressure Liquid Chromatography for Assay in Ciprofloxacin hydrochloride Drug Substances. American Journal of Analytical Chemistry, 6, 719-730. http://dx.doi.org/10.4236/ajac.2015.69069 
tive, simple, accurate, cost effective, and it is applicable for stability studies and routine qualitycontrol analysis in the pharmaceutical industries.

\section{Keywords}

\section{Ciprofloxacin Hydrochloride, Fluoroquinolone, HPLC}

\section{Introduction}

Ciprofloxacin is a synthetic chemotherapeutic antibiotic of the fluoroquinoline drug [1]-[3]. It is a second-generation fluoroquinoline antibacterial inhibitor [4] [5]. It inhibits pathogenic bacteria by interfering with the enzymes that cause DNA to rewind after being copied; it can prevent the synthesis of DNA and protein molecule. Therefore, Ciprofloxacin hydrochloride drug molecule can treat bacterial infections [6]-[8]. Ciprofloxacin was first patented in 1983 by Bayer A.G. and then accepted by the United States Food and Drug Administration (FDA) in the year 1987. Ciprofloxacin is 1-cyclopropyl-6-fluoro-1, 4-dihydro-4-oxo-7-(1-piperazinyl)-3-quinolinecarboxylic acid. Its empirical formula is $\mathrm{C}_{17} \mathrm{H}_{18} \mathrm{FN}_{3} \mathrm{O}_{3}$ and its molecular weight of this molecule $331.4 \mathrm{~g} / \mathrm{mol}$. It is slightly yellowish to light yellow crystalline product. Ciprofloxacin hydrochloride (USP) is the monohydrochloride monohydrate salt of ciprofloxacin. It is a faintly yellowish to light yellow crystalline substance with a molecular weight of $385.8 \mathrm{~g} / \mathrm{mol} . \mathrm{C}_{17} \mathrm{H}_{18} \mathrm{FN}_{3} \mathrm{O}_{3} \mathrm{HCl} \cdot \mathrm{H}_{2} \mathrm{O}$ is the empirical formula of Ciprofloxacin hydrochloride monohydrate [9]. The structure of studied ciprofloxacin hydrochloride salt showed in Figure 1. Quinolones have two types of ring structure, a naphthyridine nucleus with nitrogen atom at 1 and 8 positions, a nucleus with nitrogen atom in position 1 and it is referred as the quinoline moiety. It contains the keto oxygen functional group at carbon -4 and a carboxylic side chain at carbon -3 . In addition, the ciprofloxacin has a piperazinyl group at carbon -7 . The presence of both carboxyl and amine groups makes the acid-base behavior of the drug influenced by the physico-chemical properties of the solvent [10]. Hence, the presence of aromatic delocalized $\pi$-electrons and electronegative heteroatoms, the molecules are highly polarizable and liable to a different specific interactions with polar solvents. Ciprofloxacin is used to cure a wide variety of infections, including infections at joints and bones, endocarditis, gastroenteritis, respiratory tract infections, cellulitis, urinary tract infections, prostatitis, anthrax, and chancroid [11].

In addition, ciprofloxacin is available as a generic drug under a variety of different brand names and is also available for limited use in veterinary medicine. These may be either new entities or partial structural modifications of the existing one. Very often there is a time delay from the date of introduction of a drug into the market to the date of inclusion in pharmacopoeias. This happens because of the likely uncertainties in the continuous and wider usage of the drugs, results of new toxicities, growth of patient resistance and introduction of better drugs by contenders. Under such conditions, finalized analytical procedures for these drugs may not be available in the pharmacopoeias. It becomes necessary to develop newer analytical methods for such drugs.

Spectrophotometric analytical assay methods [12] [13] involve the measurement of absorbance of samples containing only one absorbing analyte. The pharmaceutical analyst frequently faces the situation where the concentration of one or more substances is required in samples known to contain other absorbing substances, which potentially interferes in the same measuring wavelength. Due to the interferences, Simple Spectrophotometric methods may not get accurate assay for the sample but separation of the interferences in a single experiment and

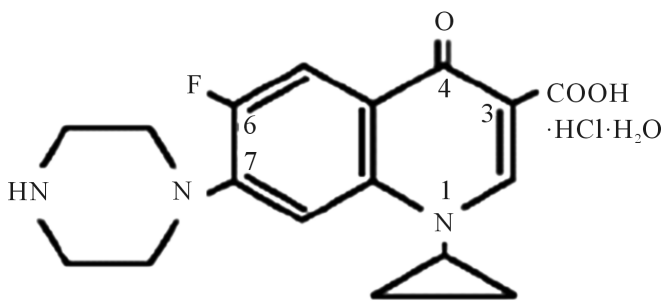

Figure 1. Chemical structure of Ciprofloxacin Hydrochloride monohydrate. 
accurate, precise with good reproducibility of assay determination achieved by using High Pressure Liquid Chromatographic method [14]-[18].

In view of the above facts, it encourages us to investigate an analytical stability indicative method development and validate by high pressure liquid chromatography for assay in ciprofloxacin hydrochloride drug substances. The conformed Reverse Phase-High Pressure Liquid Chromatographic method procedure is a finely resolved, simple and good stability indicative method to determine the assay of Ciprofloxacin hydrochloride for routine quality-control analysis in pharmaceutical testing laboratories.

\section{Experimental [19]-[22]}

\subsection{Materials and Reagents}

Ciprofloxacin hydrochloride drug substances and related impurities was gifted by local Pharmaceutical industry, acetonitrile (HPLC grade) was purchased from Rankem Lab, HPLC grade water (Millipore), orthophosphoric acid (AR grade) from spectrochem (India), hydrochloric acid (AR grade) from sd-fine chemicals, hydrogen peroxide (AR grade) from CDH fine chemicals, sodium hydroxide (AR grade) from SDFCL and triethyamine (AR grade) was purchased from spectrochem (India).

\subsection{Instrumentation}

UV-Visible spectrophotometer Perkin Elmer’s LAMDA 25. For Chromatography an Agilent 1100 series Quaternary pump with diode array detector/UV detector with chemstation software and separations of analytes and determination of the compound was performed with Inertsil C18 column $(250 \mathrm{~mm} \times 4.6 \mathrm{~mm}$ I.D; particle size 5 $\mu \mathrm{m}$ ) maintained at $35^{\circ} \mathrm{C}$. Weigh the sample done on Sartorius analytical balance with sensitivity of $0.01 \mathrm{mg}$. Mobile phase $\mathrm{pH}$ adjustments made with digital pH Meter Elico.

\subsection{Chromatographic Conditions}

The Reversed phase High Pressure Liquid Chromatography analysis was carried out at $35^{\circ} \mathrm{C}$ temperature. The components were eluted by gradient method programme (Table 1) with a mobile phase-A (pipette and transfer $1.5 \mathrm{~mL}$ of orthophosphoric acid to $1000 \mathrm{~mL}$ of water and mix well then adjust $\mathrm{pH}$ to 3.0 with triethylamine.) and mobile phase-B (acetonitrile). The mobile phases were filtered through $0.45 \mu \mathrm{m}$ membrane filter (Millipore). Flow rate is $0.7 \mathrm{~mL} / \mathrm{min}$ and the injection volume for standard and sample was $10.0 \mu \mathrm{L}$. The eluents were measured at a wavelength of $278 \mathrm{~nm}$.

\subsection{Analytical Method Development}

For developing a new chromatography method the standard and sample solubility was checked in water, acetonitrile and mixture of mobile phase-A and mobile phase-B in the ratio 80:20. The standard and sample was freely soluble with the above mixture of mobile phase-A and mobile phase-B. Then a solution of standard was scanned on UV Spectrophotometer to identify the maximum absorbance of wavelength. Maxima UV absorbance observed at Wavelength $278 \mathrm{~nm}$. Hence this wavelength has been chosen for detection in analysis of Ciprofloxacin hydrochloride. Since ciprofloxacin hydrochloride was freely soluble in mixture of mobile phase-A and

\begin{tabular}{ccc}
\hline Table 1. The gradient method programme. \\
\hline Time in minutes & Mobile Phase A (In \%) & Mobile Phase B (In \%) \\
\hline 0.0 & 82 & 18 \\
5.0 & 82 & 18 \\
6.0 & 95 & 5 \\
12.0 & 95 & 5 \\
13.0 & 82 & 18 \\
30.0 & 82 & 18 \\
\hline
\end{tabular}


mobile phase-B in the ratio 80:20 was kept as diluent for sample and standard preparations. Gradient mobile phase elution programme was finalized for better resolution. Equilibrated the column with initial composition of the mobile phases A and mobile phases B in the gradient method. Injected Blank (Diluent) one injection, Standard solution five injections and checked the system suitability, the relative standard deviation for ciprofloxacin hydrochloride peak in standard solution is not more than $2.0 \%$. Its theoretical plates for peak are not less than 2000; the tailing factor of peak is not more than 2.0. The system suitability parameters pass and then injected the sample solution in duplicate, recorded main peak response.

\subsection{Standard Solution Preparation}

Weigh and transfer quantitatively about $100.0 \mathrm{mg}$ of ciprofloxacin hydrochloride standard to $10.0 \mathrm{~mL}$ volumetric flask, dissolve and dilute to volume with diluent. Further dilute $1.0 \mathrm{ml}$ of above solution to $100 \mathrm{ml}$ with the diluent and mix.

\subsection{Sample Solution Preparation}

Weigh and transfer accurately about $12.0 \mathrm{mg}$ of ciprofloxacin hydrochloride sample to $25.0 \mathrm{~mL}$ volumetric flask, dissolve and dilute to volume with diluent. Further diluent $2.0 \mathrm{ml}$ of above solution to $10.0 \mathrm{ml}$ with the diluent and mix.

\section{Results and Discussion}

\subsection{Chromatographic Method Development}

As per the spectrum of UV spectrophotometer, ciprofloxacin hydrochloride has been showed wavelength was at $278 \mathrm{~nm}(\lambda \max )$. Hence $278 \mathrm{~nm}$ was selected for determination of ciprofloxacin hydrochloride (Figures 2(a)). The method was optimized to separate major impurity and degradation product peaks formed under different stress conditions. The main target of the chromatographic method is to separate closely eluting peaks of the sample, mainly ethylenediamine compound (ciprofloxacin impurity-C) and 7-chloro-1-cyclopropyl-4-oxo-6(piperazin-1-yl)-1,4-dihydroquinoloine-3-carboxylic acid hydrochloride salt (Ciprofloxacin Related compoundA) peaks. The degradation samples were run using different columns with same stationary phase like C18 and mobile phases containing buffers like Acetate and phosphate.

The Gradient mode method has been worked out to separate very closely eluting impurity peaks. To improve response, peak shape and resolution between the peaks the method was tried at different column temperatures. But the separation, response of peaks and peak shapes were satisfactory in the adopted chromatographic conditions only, mainly the ciprofloxacin impurity-C at RRT 0.74 and ciprofloxacin related compound-A at RRT 1.17. It indicated that the gradient mode method with acetonitrile as an organic modifier in mobile phase was successful in separating the main component from all other chromatographic degradation products (Figures 2(b)(g)).

\subsection{Column Selection}

Based on the retention, better peak shape of the compound, good column life on usage and easy availability with low cost, Inertsil C18 $(250 \times 4.0 \mathrm{~mm}$; $5 \mu \mathrm{m})$ column was selected as suitable column for analysis of Ciprofloxacin Hydrochloride.

\section{Method Validation}

Validation is a process of proving or documenting, analytical method provides analytical data, for the intended use. There are many reasons for the need to validate analytical procedures. To assuring the Quality and achieving Quality control requirements, to achieve acceptance of the product by international agencies, mandatory require purpose for accreditation as per ISO 17025 guidelines. The Code of Federal Regulations (CFR) 311.165c explicitly states that "the specificity, sensitivity, recovery and reproducibility of test methods employed by the firm shall be established and documented".

According to FDA guidance document, a stability-indicating method is "a validated quantitative analytical procedure that can detect the changes with time in the pertinent properties of the drug substances and finished 
S. Shrinivas, M. Revanasiddappa

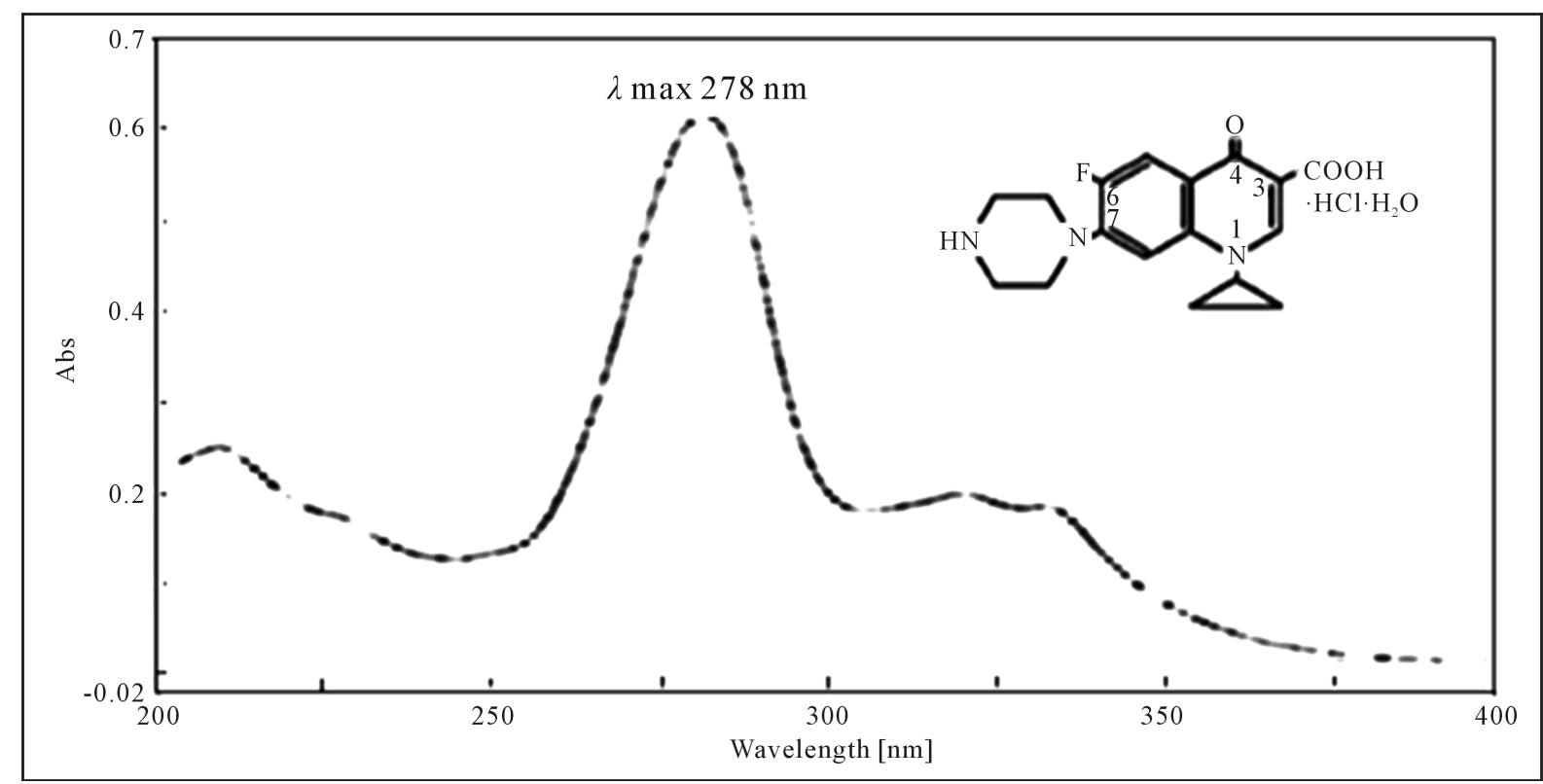

(a)

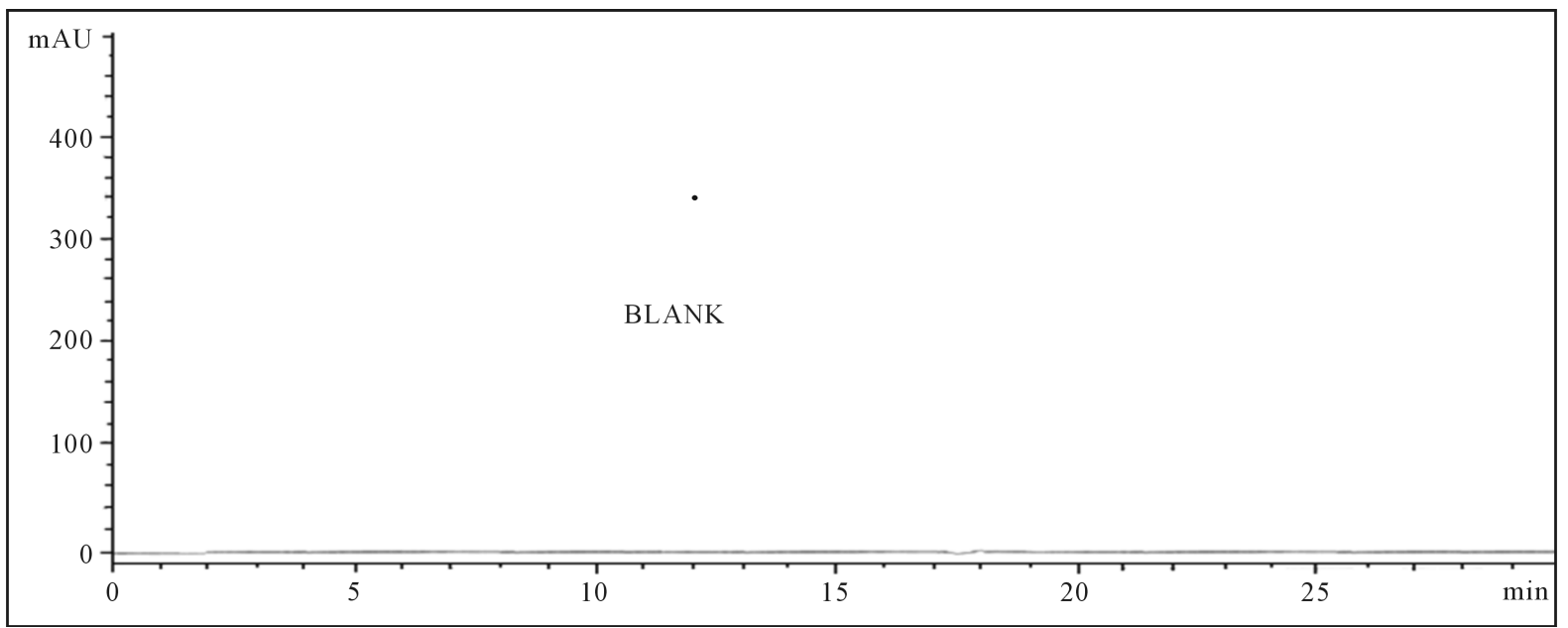

(b)

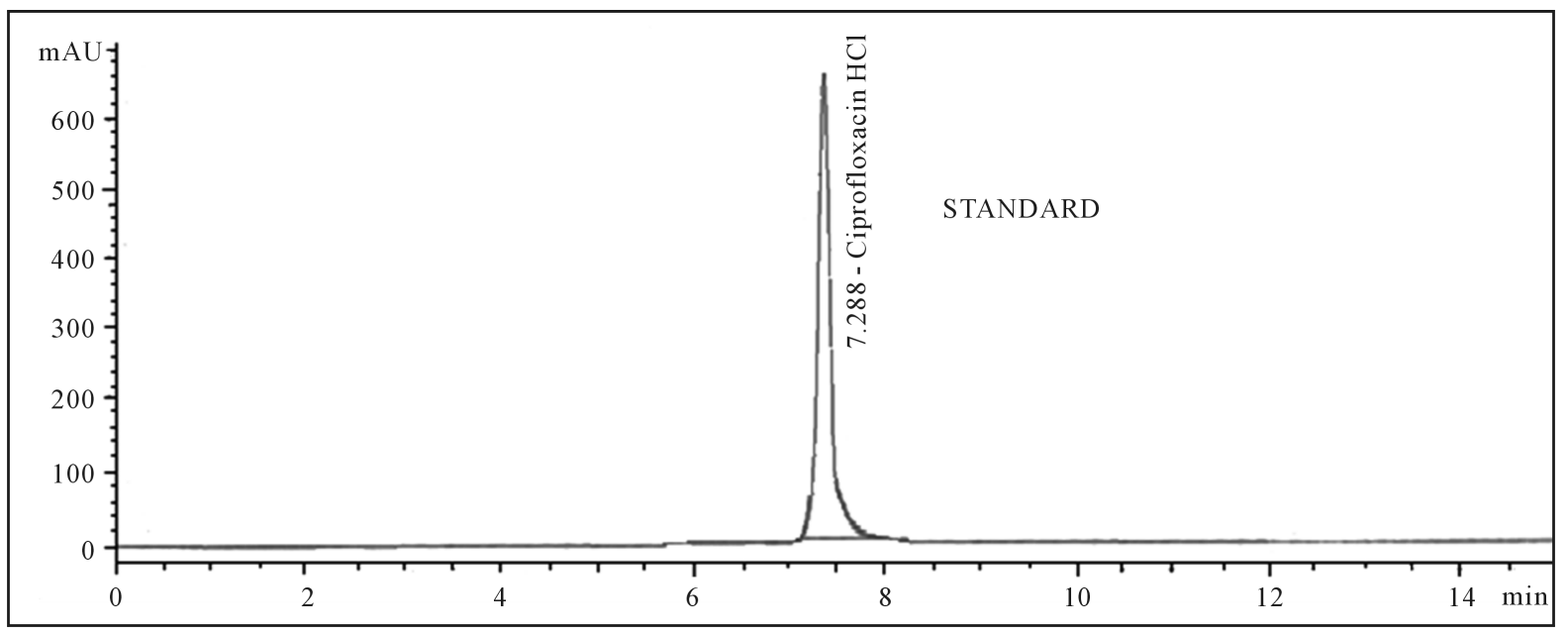

(c) 


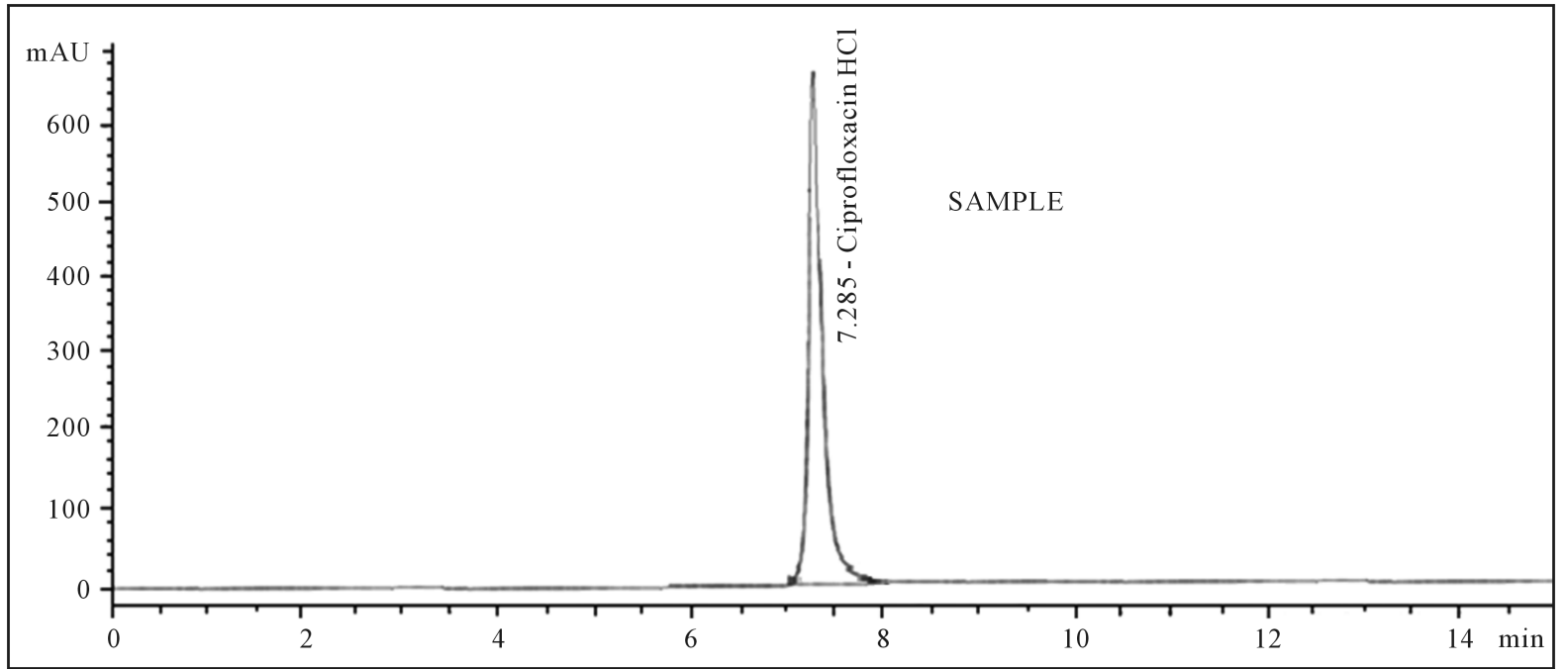

(d)

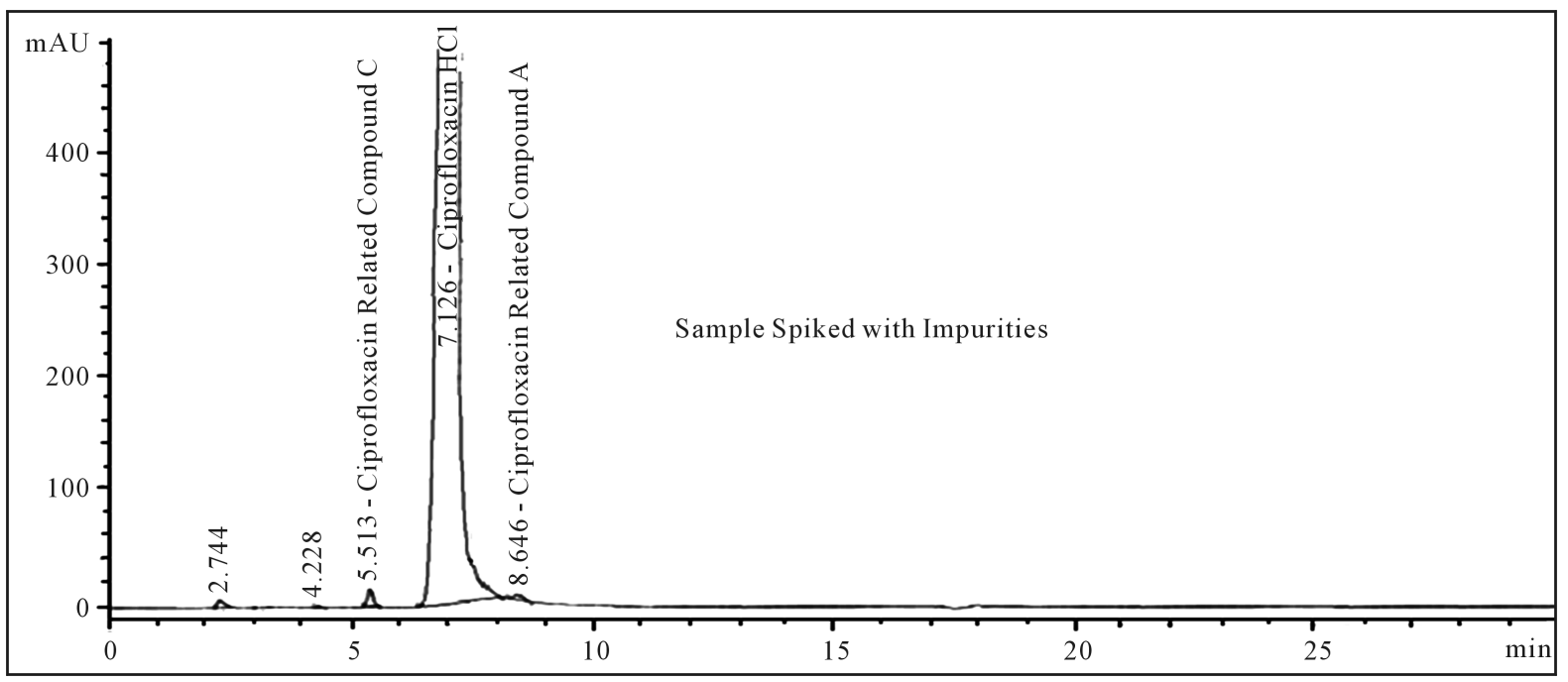

(e)

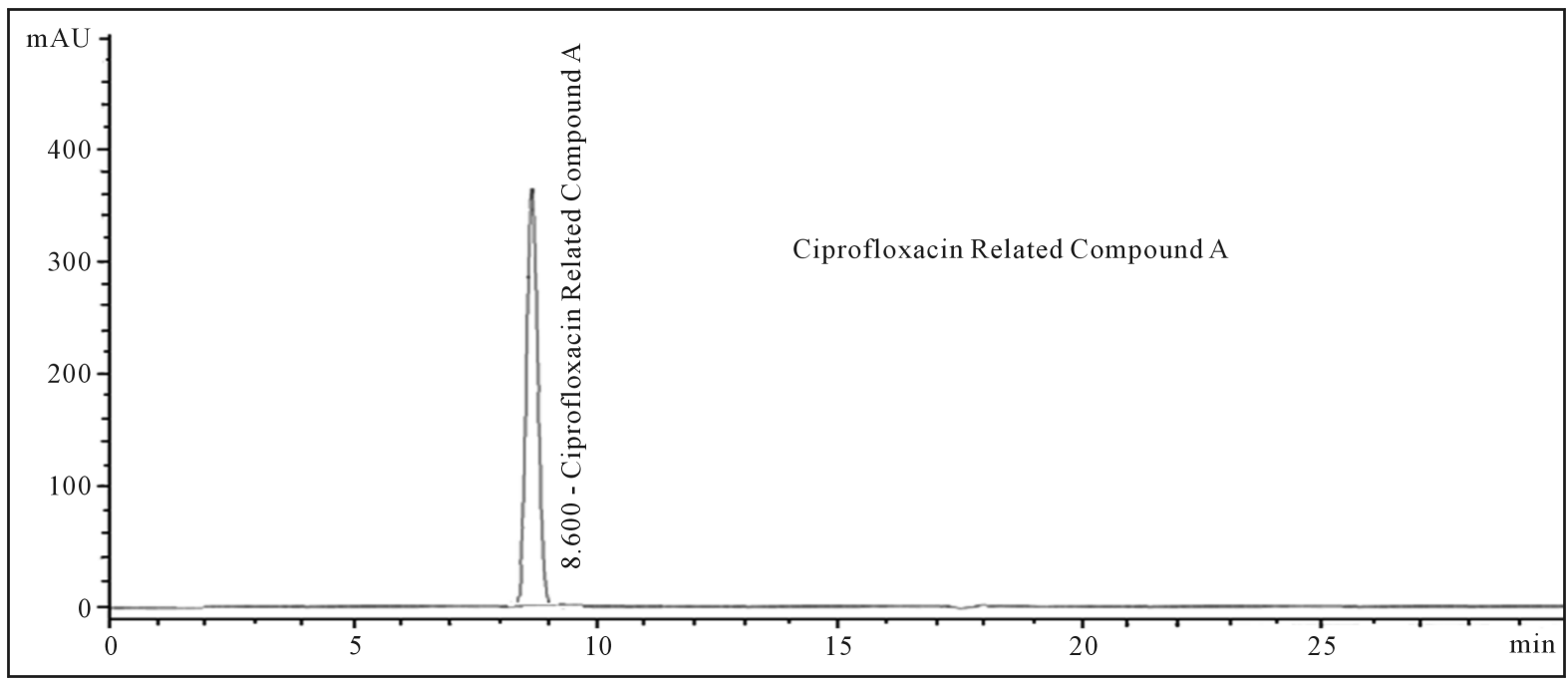

(f) 


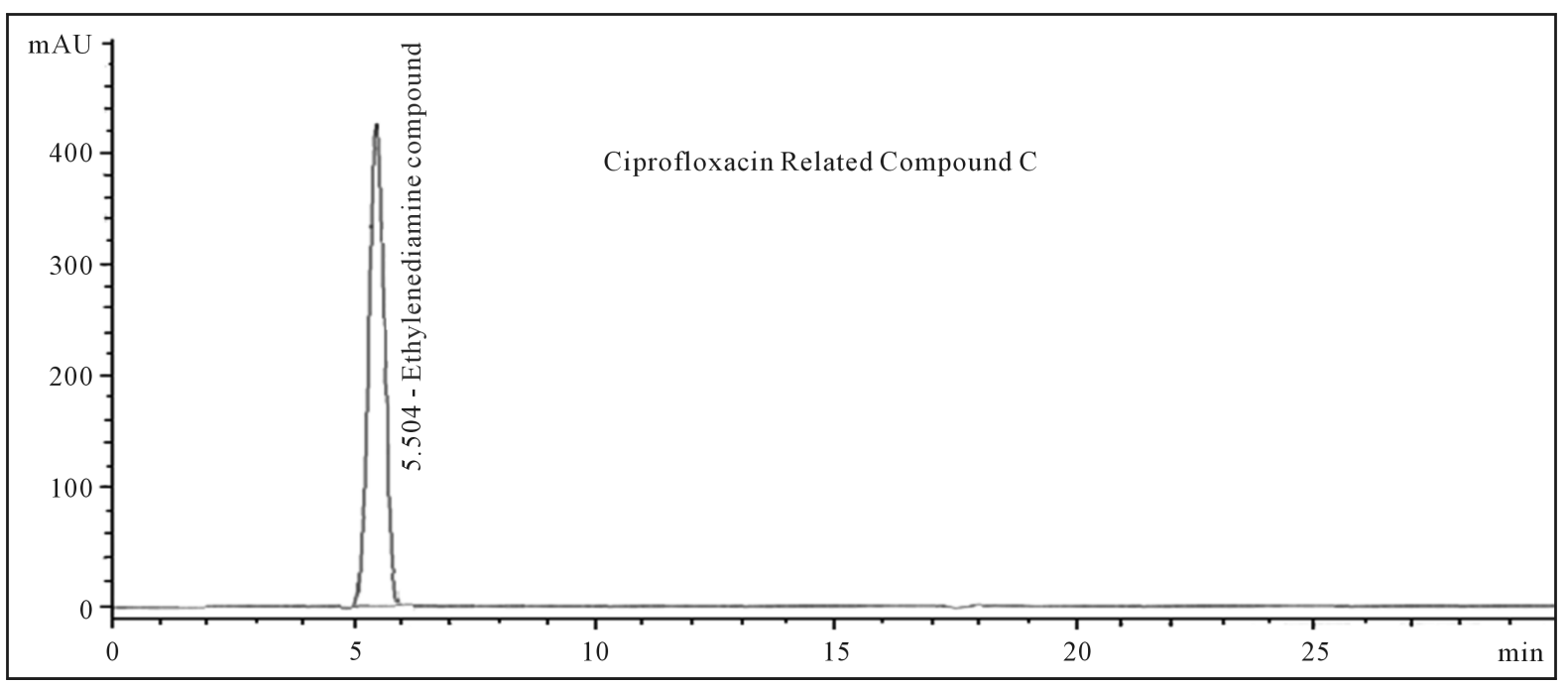

(g)

Figure 2. (a) A typical UV spectrum of ciprofloxacin hydrochloride; (b) A typical chromatogram of blank; (c) A typical chromatogram of standard; (d) A typical chromatogram of sample; (e) A typical chromatogram of sample spiked with impurities; (f) A typical chromatogram of ciprofloxacin related compound A; (g) A typical chromatogram of ethylenediamine compound.

product. A stability-indicating method measures accurately the active ingredients, without interference from the stressed products, process impurities, excipients or other potential impurities”. Hence the stability-indicating method must be validated. The developed RP-HPLC assay method of ciprofloxacin hydrochloride drug substances was extensively validated as per ICH guidelines using the following parameters.

\subsection{System Suitability}

To verify that the analytical system is working properly and can give accurate and precise results, the system suitability parameters are to be checked by injecting the one injection of blank solution and five injections of standard solution into chromatographic system. Recorded chromatograms, checked system suitability. The Relative standard deviation of ciprofloxacin hydrochloride peak area for five injections of standard solution was $0.5 \%$. The tailing factor and theoretical plates was 1.2 and 12150 . From these results, it concluded that the system is suitable for analytical method validation.

\subsection{Specificity}

Specificity is the ability of analytical method to assess unequivocally the analyte in the presence of component that may be expected to be present, such as impurities, degradation products and matrix components. Performed the specificity parameter of the method by injecting diluent (Blank), standard and sample solution into the HPLC system, then recorded the retention time of each injected solution. Observed no interferences at diluent peak and also peak of ciprofloxacin hydrochloride was pure.

\subsection{Stress Studies}

Stress testing of drug substances can help to identify the likely degradation products, which can in tern help establish the degradation pathways and the intrinsic stability of the molecule. All stress decomposition studies were performed at a $100 \mathrm{ppm}$ concentration of ciprofloxacin hydrochloride sample. Acid hydrolysis was performed in $0.1 \mathrm{~N}$ and $1.0 \mathrm{~N}$ Hydrochloric acid at $80^{\circ} \mathrm{C}$ for 4 hours. The study in basic condition was carried out in $0.1 \mathrm{~N}$ and $1.0 \mathrm{~N}$ sodium hydroxide solution at $80^{\circ} \mathrm{C}$ for 4 hours. For neutral stressed condition, drug substances dissolved in water and refluxed at $80^{\circ} \mathrm{C}$ for 4 hours, oxidation stressed study were carried out on water bath at $80^{\circ} \mathrm{C}$ for 4 hours in $3 \%$ hydrogen peroxide solution. Sample exposed to sun light for 8 hours, photo degradation studies were carried out by exposing the sample to UV light for 8 hours (254 nm and $356 \mathrm{~nm}$ ), The drug sub- 
stances was exposed to dry heat by keeping the sample in oven at $80^{\circ} \mathrm{C}$ for 6 hours. Sample were withdrawn at appropriate time and subjected to RP-HPLC analysis after suitable dilution (Table 2).

Diluent peaks were not interfering with ciprofloxacin hydrochloride peak. Degradation was observed in Acid, Alkali, Peroxide stressed conditions and sunlight exposed condition. The degradation products generated are well separated from ciprofloxacin hydrochloride peak. The ciprofloxacin hydrochloride peak is pure. Hence, the assay method was considered specific and stability indicating.

\subsection{Precision of Test Method}

The precision of an analytical method is the degree of agreement among individual test results when the method is applied repeatedly to multiple sampling of homogeneous sample. The precision of analytical method is usually expressed as the standard deviation or relative standard deviation (Coefficient of variation) of series of measurements.

\subsubsection{System Precision}

The system precision is checked by using standard chemical substance to ensure that the analytical system is working properly. The retention time and area response of six determinations should be measured and calculate relative standard deviation. Then, the injected a blank solution of one injection and standard solution six injections into chromatograph. Recorded chromatograms, calculated the relative standard deviation of the retention time of ciprofloxacin hydrochloride peak at 7.2 minute is $0.5 \%$ and relative standard deviation of the area response of ciprofloxacin hydrochloride peak obtained from six injections of standard solution is $0.2 \%$. Hence it was concluded that the system precision parameter meets the requirement of validation.

\subsubsection{Intra-Day and Inter Day Precision}

The precision of the assay method was evaluated by carrying out six times of same sample as per analytical procedure against qualified standard. The percentage of relative standard deviation of six assay values was calculated. Different analyst from the same laboratory evaluated the intermediate precision of the method (Table 3).

\begin{tabular}{|c|c|c|c|}
\hline Conditions & Peak purity* & Assay in \% & Purity factor \\
\hline As such sample preparation & $\mathrm{P}$ & 101.0 & 999.899 \\
\hline $\begin{array}{l}\text { Stressed with } 0.1 \mathrm{~N} \mathrm{HCl} \text { at } 80^{\circ} \mathrm{C} \text { for } 4 \text { hours } \\
\text { and neutralized with } 0.1 \mathrm{~N} \mathrm{NaOH}\end{array}$ & $\mathrm{P}$ & 99.4 & 999.920 \\
\hline $\begin{array}{l}\text { Stressed with } 1.0 \mathrm{~N} \mathrm{HCl} \text { at } 80^{\circ} \mathrm{C} \text { for } 4 \text { hours } \\
\text { and neutralized with } 1.0 \mathrm{~N} \mathrm{NaOH}\end{array}$ & $\mathrm{P}$ & 87.0 & 999.872 \\
\hline $\begin{array}{c}\text { Stressed with } 0.1 \mathrm{~N} \mathrm{NaOH} \text { at } 80^{\circ} \mathrm{C} \text { for } 4 \text { hours } \\
\text { and neutralized with } 0.1 \mathrm{~N} \mathrm{HCl}\end{array}$ & $\mathrm{P}$ & 98.7 & 999.922 \\
\hline $\begin{array}{c}\text { Stressed with } 1.0 \mathrm{~N} \mathrm{NaOH} \text { at } 80^{\circ} \mathrm{C} \text { for } 4 \text { hours } \\
\text { and neutralized with } 1.0 \mathrm{~N} \mathrm{HCl}\end{array}$ & $\mathrm{P}$ & 94.2 & 999.934 \\
\hline $\begin{array}{l}\text { Stressed with } 3 \% \text { hydrogen peroxide at } 80^{\circ} \mathrm{C} \\
\text { for } 4 \text { hours and neutralized with water }\end{array}$ & $\mathrm{P}$ & 96.5 & 999.890 \\
\hline Exposed to sunlight for 8 hours and cooled & $\mathrm{P}$ & 100.9 & 999.906 \\
\hline $\begin{array}{l}\text { Exposed to UV light for } 8 \text { hours } \\
\quad(254 \mathrm{~nm} \text { and } 356 \mathrm{~nm})\end{array}$ & $\mathrm{P}$ & 96.0 & 999.930 \\
\hline Exposed to Dry heat at $80^{\circ} \mathrm{C}$ for 6 hours & $P$ & 90.5 & 999.937 \\
\hline Stressed with water at $80^{\circ} \mathrm{C}$ for 4 hours & $\mathrm{P}$ & 96.0 & 999.931 \\
\hline
\end{tabular}

Peak purity": "p” indicates ciprofloxacin hydrochloride peak is pure, which conformed by diode array detector and Agilent chemstation software. 
Table 3. The results table of precision.

\begin{tabular}{ccc}
\hline \multirow{2}{*}{ Sr.No } & \multicolumn{2}{c}{ \% Assay } \\
\cline { 2 - 3 } & Intra-day precision & Inter-day precision \\
\hline 2 & 100.6 & 100.5 \\
3 & 100.4 & 101.4 \\
4 & 100.3 & 101.5 \\
5 & 100.4 & 101.6 \\
6 & 101.6 & 102.2 \\
Average & 100.5 & 102.1 \\
\% RSD & 100.6 & 101.6 \\
\end{tabular}

\subsection{Stability in Analytical Solution}

The stability in analytical solution is evaluated by injecting the standard and sample solution at regular intervals. The standard solution is stable up to 38 hours at Room temperature $\left(25^{\circ} \mathrm{C}\right)$ with the percent difference $0.4 \%$ and sample solution is stable up to 35 hours at Room temperature $\left(25^{\circ} \mathrm{C}\right)$ with the percent difference $1.7 \%$.

\subsection{Linearity}

The linearity of an analytical method is its ability to elicit test results that are directly, or by a well-defined mathematical transformation, proportional to the concentration of analyte in samples within a given range. Linearity test solution for the assay method were prepared from stock solution at seven different concentration levels (50\%, 80\%, 90\%, 100\%, 110\%, 120\% and 150\%) of the target assay concentration of ciprofloxacin hydrochloride (100 ppm) and $10 \mu \mathrm{L}$ of each solution was injected into the high pressure liquid chromatography system and recorded the peak area response of the chromatogram, also precision has been performed at lower and higher concentration levels. A graph was plotted to concentration in ppm on X-axis verses Peak area response on Y-axis. Calculated slope, intercept, correlation coefficient and regression coefficient (R square) for the linearity level solutions. Linearity graph is showed in Figure 3. Linearity results of the method are presented in Table 4.

From the statistical treatment of the linearity data of ciprofloxacin hydrochloride, it is clear that the response of ciprofloxacin $\mathrm{HCl}$ is linear between $50 \%$ to $150 \%$ level. The Correlation coefficient and regression coefficients were more than 0.998 . In addition, the analysis of residuals show that the values are randomly scattered around zero, which shows good fit to the linear model. To evaluate whether the y-intercepts were significantly different from zero, the P-value was determined. The P value is $>0.05$ then intercept is statistically equal to zero. For Ciprofloxacin hydrochloride $\mathrm{P}$ value is 0.20 . Hence it is statistically equal to zero. In addition, the origin is within the lower and the upper limit of the $95 \%$ of Confidence interval, that gives high degree of confidence to the value obtained for intercept. Moreover, the value of the intercept is within the $\pm 2.0 \%$ of the area response at $100 \%$ level.

\subsection{Accuracy}

The accuracy of an analytical method is the closeness of test results obtained by that method to the true value (Standard value). The study of recovery of ciprofloxacin hydrochloride was evaluated in triplicate at three concentration levels, i.e. 50\%, 100\% and 150\% of working concentration (100 ppm) of the sample. The percentage of recoveries were calculated and found it be as within the limits (Table 5).

\subsection{Range}

The range of Analytical Method is the interval between the upper and lower levels of analyte that has been 


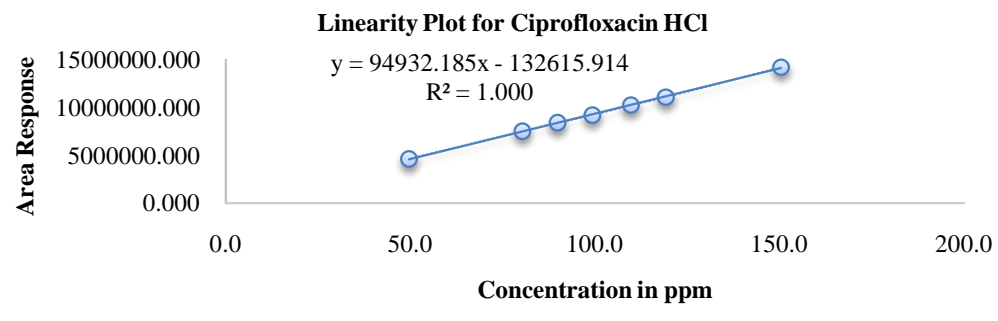

Figure 3. Linearity graph.

Table 4. The results table of Linearity.

\begin{tabular}{|c|c|c|}
\hline \% Level & Concentration in ppm & Area response \\
\hline 50 & 49.6598 & 4628113.962 \\
\hline 80 & 80.4016 & 7523524.857 \\
\hline 90 & 89.8606 & 8408472.042 \\
\hline 100 & 99.3197 & 9213073.152 \\
\hline 110 & 109.7246 & 10275208.117 \\
\hline 120 & 119.1836 & 11106062.170 \\
\hline 150 & 150.3983 & 14231940.974 \\
\hline \multicolumn{2}{|c|}{ Correlation coefficient } & 1.000 \\
\hline \multicolumn{2}{|c|}{ Regression coefficient } & 1.000 \\
\hline \multicolumn{2}{|c|}{ Slope } & 94932.185 \\
\hline \multicolumn{2}{|c|}{ Intercept } & -132615.9141 \\
\hline \multicolumn{2}{|c|}{ \% Intercept } & -1.4 \\
\hline
\end{tabular}

Table 5. The results table of accuracy.

\begin{tabular}{cccccc} 
Sr.No. & Levels & $\begin{array}{c}\text { Mean mg } \\
\text { Added }\end{array}$ & $\begin{array}{c}\text { Mean mg } \\
\text { Recovered }\end{array}$ & $\begin{array}{c}\text { Mean \% } \\
\text { Recovery }\end{array}$ & \% RSD \\
\hline 1 & $50 \%$ & 5.7091 & 5.7648 & 101.0 & 0.3 \\
2 & $100 \%$ & 11.3061 & 11.4258 & 101.1 & 0.5 \\
\hline & $150 \%$ & 16.9937 & 17.2446 & 101.5 & 0.2 \\
\hline
\end{tabular}

demonstrated to be determined with a suitable Accuracy and Linearity. Derived the specified ranges from accuracy and linearity studies and observed results are presented in Table 6 and Table 7. Linearity range graph and accuracy range graph is showed in Figure 4 and Figure 5.

\subsection{Robustness}

The robustness of an analytical method is a measure of its capacity to remain unaffected by small but deliberate variations in method parameters and provides an indication of its reliability during normal usage. To determine the robustness of the method the experimental conditions were deliberately altered by change in column temperature $\pm 5^{\circ} \mathrm{C}$, change in flow rate $\pm 0.2 \mathrm{~mL} / \mathrm{min}$ and change in mobile phase $\mathrm{pH} \pm 0.2$ units. The system suitability parameters are passed for all the conditions and the results for assay were evaluated. 
Table 6. The results table of Accuracy range.

\begin{tabular}{|cc|}
\hline \multicolumn{2}{c}{ Accuracy range } \\
\hline Level (Concentration in \%) & Mean area response \\
\hline 50 & 4620089.731 \\
100 & 9157029.499 \\
150 & 13820434.750 \\
Correlation Coefficient & 1.000 \\
RSD & $0.3 \%$ \\
\hline
\end{tabular}

Table 7. The results table of Linearity range.

\begin{tabular}{|cc|}
\hline \multicolumn{2}{|c|}{ Linearity range } \\
\hline Level (Concentration in \%) & Mean area response \\
\hline 50 & 4628113.962 \\
100 & 9213073.152 \\
150 & 14231940.97 \\
Correlation Coefficient & 1.000 \\
\hline
\end{tabular}

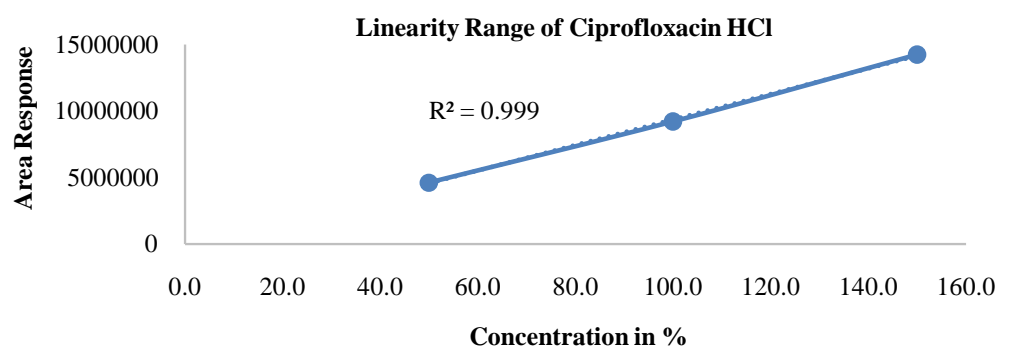

Figure 4. Linearity range graph.

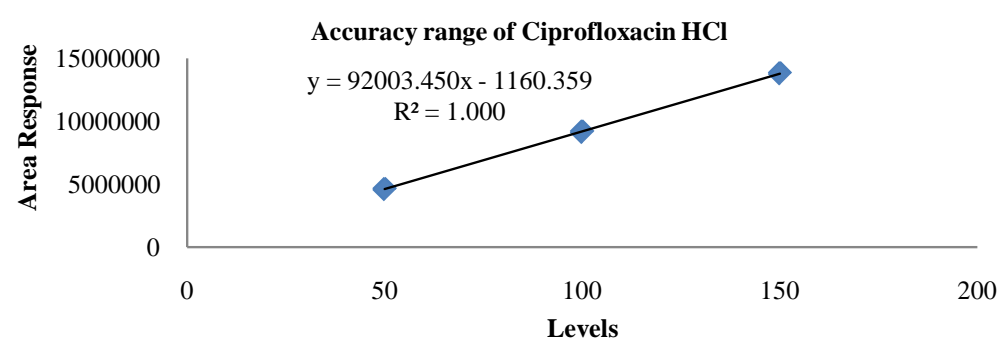

Figure 5. Accuracy range graph.

\section{Conclusion}

The proposed reversed phase high pressure liquid chromatographic method with a novel gradient mode was found to be a simple, specific, linear, precise, robust and accurate. The method was completely validated showing satisfactory data for all the method validation parameters tested. The developed method is stability indicative and can be used for quantitative determinations of the Ciprofloxacin hydrochloride in presence of degradation products in stability by the Pharmaceutical industries. 


\section{Acknowledgements}

The authors are thankful to the management of Sri Lakshmi Bhargavi Pharmaceuticals Pvt Ltd for supporting the work and also the Cooperation for the research from the colleagues of Analytical Research and Development.

\section{References}

[1] Drusano, G.L., Standiford, H.C., Plaisance, K., Forrest, A., Leslie, J. and Caldwell, J. (1986) Absolute Oral Bioavailability of Ciprofloxacin. Antimicrobial Agents and Chemotherapy, 30, 444-446. http://dx.doi.org/10.1128/AAC.30.3.444

[2] Hilliard, J.J., Krause, H.M., Bernstein, J.I., Fernandez, J.A., Nguyen, V., Ohemeng, K.A. and Barrett, J.F. (1995) A Comparison of Active Site Binding of 4-Quinolones and Novel Flavone Gyrase Inhibitors to DNA Gyrase. Advances in Experimental Medicine and Biology, 390, 59-69. http://dx.doi.org/10.1007/978-1-4757-9203-4_5

[3] Spivey, J.M., Cummings, D.M. and Pierson, N.R. (1996) Failure of Prostatitis Treatment Secondary to Probable Ciprofloxacin-Sucralfate Drug Interaction. Pharmacotherapy, 16, 314-316.

[4] Ball, P. (2000) Quinolone Generations: Natural History or Natural Selection? Journal of Antimicrobial Chemotherapy, 46, 17-24. http://dx.doi.org/10.1093/oxfordjournals.jac.a020889

[5] Oliphant, C.M. and Green, G.M. (2002) Quinolones: A Comprehensive Review. American Family Physician, 65, 455464.

[6] Solomkin, J.S., Mazuski, J.E., Bradley, J.S., et al. (January 2010) Diagnosis and Management of Complicated Intra-Abdominal Infection in Adults and Children: Guidelines by the Surgical Infection Society and the Infectious Diseases Society of America. Clinical Infectious Diseases, 50, 133-164. http://dx.doi.org/10.1086/649554

[7] Osmon, D.R., Berbari, E.F., Berendt, A.R., Lew, D., Zimmerli, W., Steckelberg, J.M., Rao, N., Hanssen, A. and Wilson, W.R. (2012) Diagnosis and Management of Prosthetic Joint Infection: Clinical Practice Guidelines by the Infectious Diseases Society of America. Clinical Infectious Diseases, 56, e1-e25. http://dx.doi.org/10.1093/cid/cis803

[8] Ritter, J.M. and Lewis, L.D. (2008) Clinical Pharmacology and Therapeutics (Textbook). A Hodder Arnold Publication. CRC Press, Boca Raton, 423-429.

[9] US Food and Drug Administration (2009) Cipro Labeling Revision 04/06/2009 Supplement 073. Retrieved 8 September 2009.

[10] Park, H., Kim, T.H. and Bark, K. (2002) Physicochemical Properties of Quinolone Antibiotics in Various Environments. European Journal of Medicinal Chemistry, 37, 443. http://dx.doi.org/10.1016/S0223-5234(02)01361-2

[11] (2011) Ciprofloxacin Hydrochloride. The American Society of Health-System Pharmacists.

[12] Mahrouse, M.A. and Elkady, E.F. (2011) Validated Spectrophotometric Methods for the Simultaneous Determination of Ciprofloxacin Hydrochloride and Metronidazole in Tablets. Chemical and Pharmaceutical Bulletin, 59, 1485-1493. http://dx.doi.org/10.1248/cpb.59.1485

[13] Cazedey, E.C.L. and Salgado, H.R.N. (2012) Spectrophotometric Determination of Ciprofloxacin Hydrochloride in Ophthalmic Solution. Advances in Analytical Chemistry, 2, 74-79.

[14] Snyder, L.R., Kirkland, J.J. and Glajch. J.L. (1997) Practical HPLC Method Development, 2nd Edition, Wiley, Hoboken. http://dx.doi.org/10.1002/9781118592014

[15] Wu, S.-S., Chein, C.-Y. and Wen, Y.-H. (2008) Analysis of Ciprofloxacin by a Simple High-Performance Liquid Chromatography Method. Journal of Chromatographic Science, 46, 490-495. http://dx.doi.org/10.1093/chromsci/46.6.490

[16] Patel, S.A., Patel, N.M. and Patel, M.M. (2006) Simultaneous Spectrophotometric Estimation of Ciprofloxacin and Ornidazole in Tablets. Indian Journal of Pharmaceutical Sciences, 68, 665-667. http://dx.doi.org/10.4103/0250-474X.29645

[17] Patel, K.B, Thula, K.C. and Maheshwari, D.G. (2014) Stability Indicating HPLC Method for Simultaneous Estimation of Ciprofloxacin and Phenylephrine in Pharmaceutical Dosage form. Pharmacophore, 5, 262-272.

[18] Patel, N.V. and Prajapati. A.M. (2012) Q-Absorbance Ratio Spectrophotometric Method for the Simultaneous Estimation of Ciprofloxacin and Metronidazole in Their Combined Dosage Form. Journal of Pharmaceutical Science Bioscientific Research, 2, 118-122.

[19] Text and Methodology Q 2 (R1) (2011) ICH Guidelines on Validation of Analytical Procedure.

[20] Validation of Analytical Procedure Methodology (1996) ICH Harmonized Tripartite Guidelines.

[21] Text on Validation of Analytical Procedure Step-4 Q2A (1994) ICH Harmonized Tripartite Guidelines.

[22] International Conference on Harmonization (2003) Stability Testing of New Drug Substances and Products Q1A (R2). IFPMA, Geneva. 